Título artículo / Títol article: Nanobased coatings with improved NIR reflecting properties for building envelope materials: Development and natural aging effect measurement

Autores / Autors

Revel, Gian Marco ; Martarelli, Milena ; Bengochea, Miguel Ángel ; Gozalbo Nebot, Ana ; Orts Tarí, Ma José ; Gaki, Anna ; Gregou, Maria ; Taxiarchou, Maria ; Bianchin, Alvise ; Emiliani, Marco

Revista:

Cement and Concrete Composites, 2013, vol. 36

Versión / Versió:

Preprint del autor

Cita bibliográfica / Cita bibliogràfica (ISO 690):
REVEL, Gian Marco, et al. Nanobased coatings with improved NIR reflecting properties for building envelope materials: Development and natural aging effect measurement. Cement and Concrete Composites, 2013, vol. 36 , p. $128-135$

http://hdl.handle.net/10234/88789 


\title{
Nanobased coatings with improved NIR reflecting properties for building envelope materials: development and natural aging effect measurement
}

\author{
Gian Marco Revel ${ }^{\mathrm{a}}$, Milena Martarelli ${ }^{\mathrm{b}}$, Miguel Ángel Bengochea ${ }^{\mathrm{c}}$, Ana Gozalbo ${ }^{\mathrm{d}}$, Maria \\ Josè Orts $^{\mathrm{d}}$, Anna Gaki ${ }^{\mathrm{e}}$, Maria Gregou ${ }^{\mathrm{e}}$, Maria Taxiarchou ${ }^{\mathrm{e}}$, Alvise Bianchin ${ }^{\mathrm{f}}$, Marco \\ Emiliani $^{\mathrm{a} *}$ \\ ${ }^{a}$ DIISM, Università Politecnica delle Marche, Ancona, Italy \\ ${ }^{b}$ Università degli Studi e-Campus, Novedrate (CO), Italy \\ ${ }^{c}$ Keraben Grupo S.A., Nules (Castellón), Spain \\ ${ }^{d}$ Instituto de Tecnología Cerámica, Castellón, Spain \\ ${ }^{e}$ National Technical University of Athens, School of Mining and Metallurgical Engineering, Athens, Greece \\ ${ }^{f}$ MBN Nanomaterialia, Vascon di Carbonera (TV), Italy
}

\begin{abstract}
A significant contribution to the reduction of the Urban Heat Island effect and cooling energy demand is given today by the so called cool materials for the building envelope with enhanced reflecting and emitting properties. The present study shows some preliminary results of the EU project COOL-Coverings aiming at developing innovative nanobased coatings with improved Near InfraRed reflecting capabilities. The key idea is to work on a nanoscale by tuning the crystal size and distribution of selected nanostructured oxides . Cool prototypes of brown colored ceramic tiles and green acrylic paints have been developed and compared to conventional ones showing an improvement in solar reflectance without any perceptual difference in color. The material characterization has been based on the measurement of spectral reflectance on a wide wavelength range (300-2200nm) using a UV/Vis/NIR spectrophotometer. In parallel with the development of nanostructured cool materials, natural aging tests on ceramic and painted concrete tiles have been performed with the goal of identifying and measuring the effects of the main aging factors affecting reflective properties. A significant drop of solar reflectance for paints has been noticed from the very beginning of the testing period while ceramic tiles have confirmed excellent resistance to weathering. However, both for paints and tiles the effect of soiling cannot be neglected and, if combined to weathering, it can lead to a solar reflectance reduction as high as $10 \%$. This preliminary study will pave the way to a future development of dedicated accelerated aging testing procedures for cool materials.
\end{abstract}

Keywords: COOL-Coverings, nanotechnologies, solar reflectance, energy efficiency, cool roof, aging test.

\section{Introduction}

The increasing cooling energy demand in buildings together with the growing Urban Heat Island effect has raised the need for innovative materials and technologies. It has been demonstrated that the use of cool roofs can mitigate both these effects by reflecting the incident solar radiation and radiating absorbed energy toward the atmosphere, mainly during the night [1]. Some researchers [2] have estimated a potential saving of peak cooling load of $11-27 \%$ for air-conditioned buildings depending on the climatic conditions.

\footnotetext{
* Corresponding author. Address: DIISM, Università Politecnica delle Marche, via Brecce Bianche 1, Ancona 60131. Tel: +39071 2204508; fax +39 0712204801
}

E-mail address: m.emiliani@univpm.it 
Behind a simple working principle - reflecting as much as possible - cool coatings require innovative technologies and new materials. At the beginning, the concept of cool roof was only restricted to white surfaces taking advantage of their intrinsic property of reflecting light in the visible range. In recent years increasing efforts have been made to achieve comparable results also for colored coatings considering that often aesthetic quality is a priority in the choice of the building envelope system [3]. The basic idea is to increase the reflectance of conventional nonwhite materials in the Near InfraRed (NIR) while keeping the same values in the visible range (and consequently the same color). Taking into account that the sun emits more than $50 \%$ of its energy as NIR radiation, a significant improvement in building passive cooling can be achieved, even for dark colors. Recently advanced cool colored materials have been developed by including NIR reflective pigments in the basic formulation of traditional paints [4]. A comprehensive analysis has been conducted by R. Levinson et Al. [5] which have published a detailed survey of 87 organic and inorganic pigments with high NIR reflecting properties. Most of them have found application in roof products such as clay and concrete tiles, metal roofs and asphalt shingles [6] leading to an increase of solar reflectance up to $20 \%$ for most absorbing materials.

The aim of the present work is to show the improvement of NIR reflectance on paints (for building roofs and façades) and ceramic tiles (for building façade) by working on the coating nanoscale, tuning the particle size of selected nanostructured oxides [7]. Being the developed prototypes prepared by following traditional processes other variables like abrasion and adhesion resistance have not considered to be critical. Beside, ceramic tiles have been developed for building façades and differently from floor tiles, they don't require superior abrasion resistance. In the case of paints, nanostructured additives will be developed and added to commercial acrylic base paints so that abrasion and adhesion are expected to range within traditional tolerant limits.

New materials have been compared with traditional ones in terms of color matching and $\mathrm{NIR} /$ solar reflectance. More specifically innovative paints can definitely improve the solar reflectance of building roofs and façades like the concrete ones which could have poor reflective properties. In Fig. 1 the spectral reflectance of white and gray Portland cements are compared showing a difference of solar reflectance of nearly $35 \%$. Similar results were obtained also in [8] where several concrete compositions (different types of sand, rock and Portland cement) have been tested. For concrete surfaces a significant improvement of reflectance can be achieved, especially in the case of gray cement, by applying highly NIR reflecting coatings. 




Fig. 1: Spectral reflectance of traditional gray and white cement.

Together with improved reflective properties, the innovative building coatings are also expected to have optimal aging resistance. The application of nanocomposite surface treatments to enhance the durability of concrete substrates has already been experimented in previous research activities. For instance in [9] different amounts of nanoclay composites have been added to a concrete substrate leading to a significant improvement of the protection performances. In the present work preliminary natural aging tests have been performed on traditional ceramic and painted concrete tiles in order to point out the main aging mechanisms and to determine the predominant factors responsible for color and reflectance degradation. Durability is one of the main issues for new materials, also considering that the higher initial investment can be paid back by the yearly cooling energy saving only if reflecting properties are preserved over the time. The main objective of these preliminary tests is to provide background information for the development of dedicated accelerated aging procedures for the new cool coatings, in agreement with guidelines provided in [10].

\section{Reflectance and color measurement}

The characterization of new cool materials has been based on the measurement of spectral reflectance on a wide wavelength range (300-2200nm) using a UV/Vis/NIR spectrophotometer (JASCO V-670) equipped with $150 \mathrm{~mm}$ integrating sphere according to standard ASTM E903 [11]. The considered spectral interval has been chosen taking into account for the large spectral interval of solar radiation.

Three main kind of information can be obtained by processing spectral reflectance data:

- SOLAR REFLECTANCE (SR): it represents the capability of a material to reflect solar radiation and it is calculated from the weighted-average of spectral reflectance $\rho(\lambda)$ from $300 \mathrm{~nm}\left(\lambda_{\min }\right)$ to $2200 \mathrm{~nm}\left(\lambda_{\max }\right)$ according to $\mathrm{Eq}(1)$ :

$$
S R=\int_{\lambda_{\min }}^{\lambda_{\max }} \frac{\rho(\lambda) \cdot I(\lambda)}{I_{\text {tot }}} d \lambda
$$

where $I(\lambda)$ is the spectral hemispherical solar irradiance (from standard ASTM G173 [12]) and $\mathrm{I}_{\text {tot }}$ is obtained by integrating $\mathrm{I}(\lambda)$ from $\lambda_{\min }$ to $\lambda_{\max }$. 
A repeatability test was performed in order to assess the accuracy of the solar reflectance measurement procedure. 30 repeated measurements on different samples were realized giving in the worst case an uncertainty on solar reflectance of $0.6 \%$ (with a level of confidence of $95 \%$ ). Repeatability assessment is important to accurately determine systematic trends in the measurement of the natural aging effects, where small variations are expected.

- NIR REFLECTANCE ( $\left.\mathrm{R}_{\mathrm{NIR}}\right)$ : it is calculated using Eq.(1), the only difference from solar reflectance is that in this case the spectral range is limited to the NIR region (7002200nm).

- CIELAB color coordinates: this color scale has been recommended by CIE for its efficacy in describing visual differences between colors. $L^{*}, a^{*}, b^{*}$ coordinates have been calculated from the CIE Tristimulus values $(\mathrm{X}, \mathrm{Y}, \mathrm{Z})$ measured with standard Color Tester (Dr. Lange Color Tester LFM1) or calculated from spectrophotometer data. The CIELAB coordinates allow to estimate the color matching with a reference material by calculating the color difference $(\Delta \mathrm{E})$ according to Eq. $(2)$ :

$$
\Delta \mathrm{E}=\sqrt{\Delta \mathrm{L}^{* 2}+\Delta \mathrm{a} *^{2}+\Delta \mathrm{b}^{2}}
$$

Usually $\Delta \mathrm{E}=1$ is the smallest color difference the human eye can distinguish, however, considering also the color tolerances typical of manufacturing processes, in the present study it will be considered a threshold $\Delta \mathrm{E}=4$ for color matching acceptance.

\section{Nanobased NIR reflecting materials}

Preparation and characterization of acrylic paints and ceramic tiles are reported in this section together with a description of nanostructured oxides exploited to improve their NIR reflective properties.

\subsection{Nanostructured oxides}

The nanostructured particles have been obtained by high and low energy ball milling. Ball milling is a top-down process whose output is a nanostructured powder material composed by aggregated particles in the micron and sub micron range and having crystal structure in the nanoscale. Two metal oxides have been used for the nanostructured powder preparation: Aluminum and Titanium (Rutile) oxides (examples of SEM nanostructures are illustrated in Fig. 2). Particle and crystal size are reported in Table 1. Particle size is given in terms of $90^{\text {th }}$ percentile (D90) of the distribution measured by laser diffraction and crystal size has been obtained by applying the Scherrer equation at the X-ray powder diffraction pattern.

Table 1: Crystal and particle size of nanostructured Aluminium and Titanium Oxides

$$
\text { Sample Crystal size Particle size }
$$

\begin{tabular}{ccc}
\hline Ti1 & $49 \mathrm{~nm}$ & $0,35 \mu \mathrm{m}$ \\
Ti2 & $28 \mathrm{~nm}$ & $<1 \mu \mathrm{m}$ \\
Ti3 & $57 \mathrm{~nm}$ & $<1 \mu \mathrm{m}$
\end{tabular}




$\begin{array}{lll}\text { A11 } & 61 \mathrm{~nm} & 0,67 \mu \mathrm{m} \\ \text { A12 } & 98 \mathrm{~nm} & 0,82 \mu \mathrm{m}\end{array}$

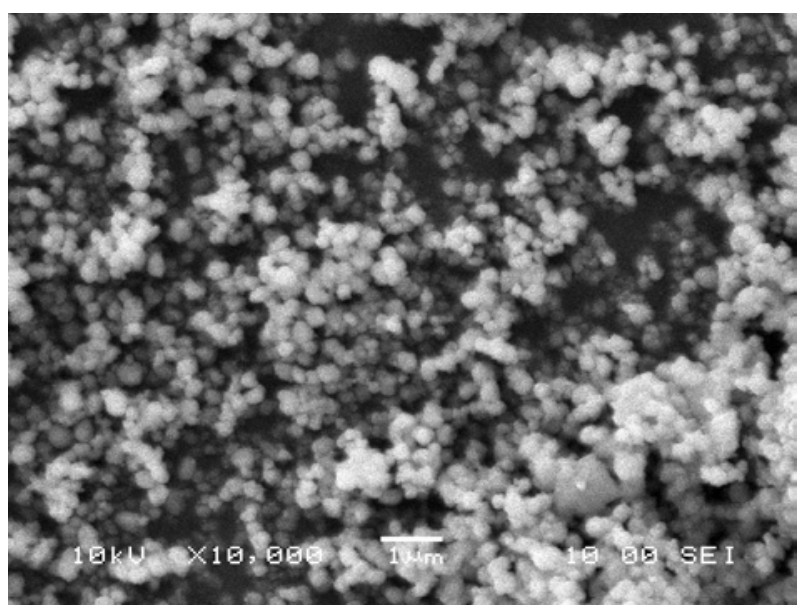

Ti1

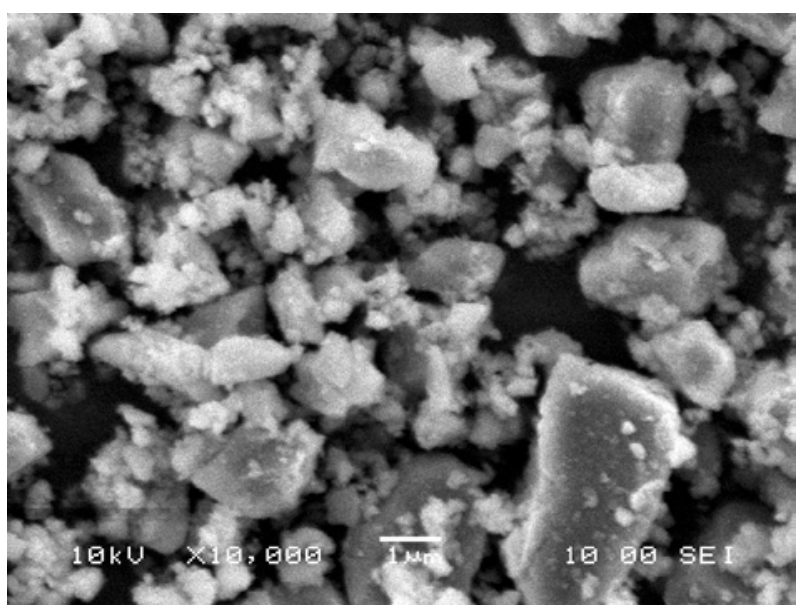

All

Fig. 2: SEM images of nanostructured Aluminium Oxides (left) and Titanium Oxides (right)

\subsection{Cool tiles}

In glazed porcelain tiles, a ceramic body covered with different layers of glazes containing pigments is fired to obtain a hard material, virtually impervious to chemical attack and aging. In these materials, the pigments are inorganic complex oxides. Compared with other building materials with similar color (paints, concrete or asphalt shingles) ceramic tiles usually absorb less solar radiation. One of the causes is that they contain pigments with rutile or spinel structures that frequently are moderate absorbers of NIR radiation. Also, their surface is smoother than that of the shingles or concrete tiles. However, in literature no approach is yet reported for cool porcelain tiles.

While for floor tiles one of the main requirements is the abrasion resistance, in the case of ceramic tiles for façade application the main properties to focus on have been identified in the aesthetics (color) and energy efficiency (capability of reflecting incident solar radiation).

In order to obtain dark brown tiles (low lightness, $\mathrm{L}^{*}$ ) with improved solar reflectance (cool tiles) a basic tint with $65 \%$ solid content was prepared by mixing, in a laboratory ball mill, appropriate proportions of the inorganic pigment, a standard porcelain tile frit and an organic solvent. The prepared tints were applied onto a porcelain tile body coated with a white glaze having high NIR reflectance $\left(\mathrm{R}_{\mathrm{NIR}}=74 \%\right)$. Finally tiles were fired with a standard porcelain tile firing cycle, up to a temperature of $1200^{\circ} \mathrm{C}$.

Several approaches have been used to engineer the tile surface:

i) Optimizing pigment concentration: the initial tint (referred as $100 \%$ ) was modified by reducing the amount of pigment to proportions of $80 \%, 60 \%$ and $50 \%$ of the original content.

ii) Optimizing layer thickness of this colored top layer in the range between $30 \mu \mathrm{m}$ and 100 $\mu \mathrm{m}$. 
iii) Adding different amounts of nanostructured $\mathrm{TiO}_{2}$ to the topcoat of $100 \mu \mathrm{m}$ thickness. Specifically two $\mathrm{TiO}_{2}$ concentrations have been considered: $2.5 \%$ and $5 \%$ referred to the solid content.

Following this strategy 9 cool tile prototypes have been realized (Table 2) and compared to 6 standard commercial tiles from the same manufacturer.

Table 2: Topcoat composition and thickness for cool tiles

\begin{tabular}{lccc}
\hline \multicolumn{1}{c}{ Sample } & $\begin{array}{c}\text { Pigment } \\
\text { concentration }\end{array}$ & Topcoat thickness & nanostrucuredTiO ${ }_{2}$ \\
\hline KB-E3 & $100 \%$ & $50 \mu \mathrm{m}$ & - \\
KB-E4 & $100 \%$ & $30 \mu \mathrm{m}$ & - \\
KB-E15 & $80 \%$ & $50 \mu \mathrm{m}$ & - \\
KB-E16 & $60 \%$ & $100 \mu \mathrm{m}$ & - \\
KB-E17 & $60 \%$ & $50 \mu \mathrm{m}$ & - \\
KB-E30 & $50 \%$ & $100 \mu \mathrm{m}$ & $5 \% \mathrm{Ti} 2$ \\
KB-E33 & $50 \%$ & $100 \mu \mathrm{m}$ & - \\
KB-E34 & $50 \%$ & $100 \mu \mathrm{m}$ & $2.5 \% \mathrm{Ti} 1$ \\
KB-E35 & $50 \%$ & $100 \mu \mathrm{m}$ & $2.5 \% \mathrm{Ti} 2$ \\
\hline
\end{tabular}
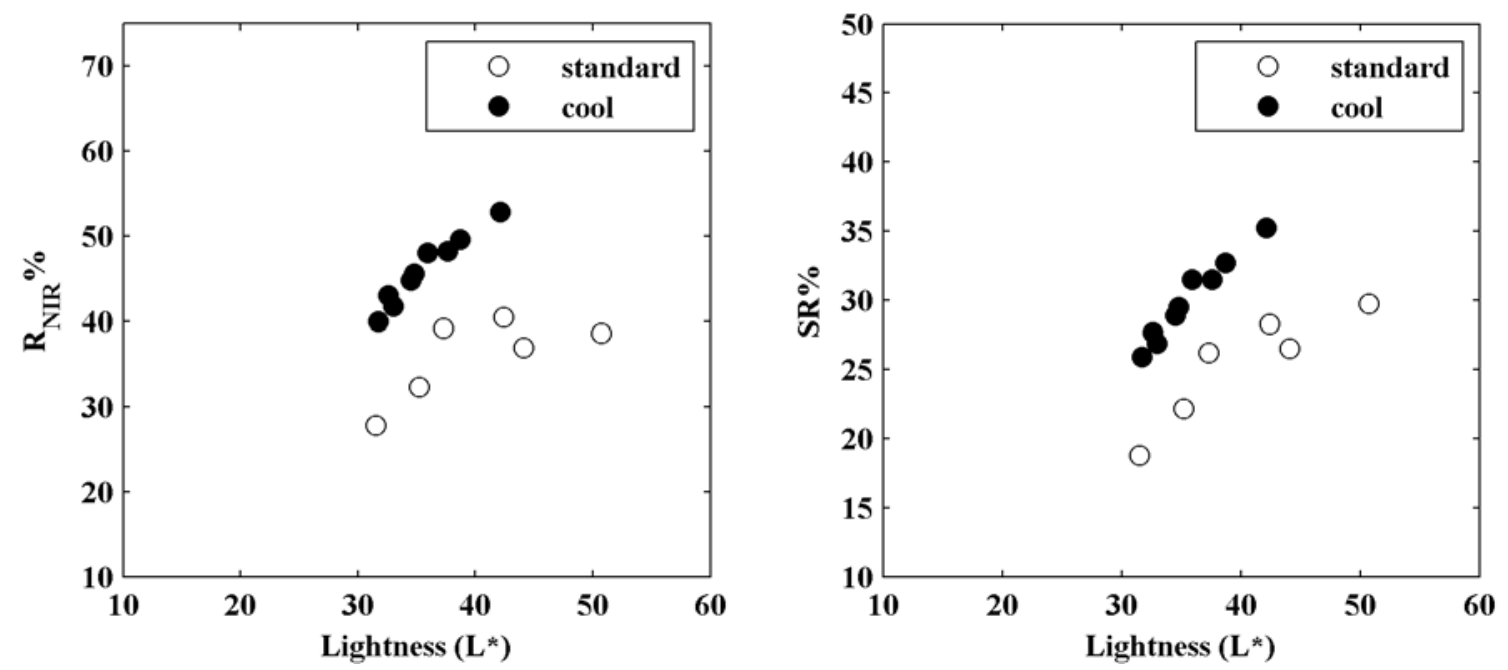

Fig. 3: Lightness $\left(L^{*}\right)$ vs. NIR reflectance (left) and Lightness $\left(L^{*}\right)$ vs. solar reflectance (right) for standard and cool ceramic tiles.

Fig. 3 shows the NIR and solar reflectance versus L* values for two series of brown tiles: 6 standard tiles and 9 cool tiles developed in the project to date. Comparing the data presented in Table 3 the following conclusions can be drawn:

- The improved samples exhibit, for the same lightness levels, a significant increase of the NIR reflectance (Fig. 3-left) which in turn means an improvement of the solar reflectance (Fig. 3-right). For instance, the cool tile KB-E3 has practically the same L* value of the standard RED BROWN one $\left(\Delta \mathrm{L}^{*}=+0.2\right)$ with an increase of $7.1 \%$ of solar reflectance. 
- In terms of tints and color difference the best color matching has been obtained between the standard tile 17-S1 and the cool tile KB-E15 $(\Delta \mathrm{E}=1.3)$. The latter combines an improved solar reflectance value $(+7.3 \%)$ with an even darker color $\left(\Delta \mathrm{L}^{*}=-0.4\right)$.

- Another remarkable result has been achieved with the sample KB-E30 which is the one with the biggest amount of nanostructured metal oxides $\left(5 \%\right.$ of $\mathrm{TiO}_{2}$ in the topcoat formulation). Among all the 2 series of conventional and cool ceramic tiles this sample has the highest NIR and solar reflectance values (respectively $52.9 \%$ and $35.2 \%$ ). If comparing it with the traditional tile 10-S4 an improvement of solar reflectance of $+6.9 \%$ has been achieved with a slightly darker color $\left(\Delta \mathrm{L}^{*}=-0.3\right)$.

Table 3: Comparison between standard and cool tiles in terms of NIR/solar reflectance and CIELAB color coordinates.

\begin{tabular}{|c|c|c|c|c|c|c|}
\hline Sample & Appearance & $\mathrm{L}^{*}$ & $a^{*}$ & $\mathrm{~b}^{*}$ & $\mathrm{R}_{\mathrm{NIR}} \%$ & SR $\%$ \\
\hline \multicolumn{7}{|l|}{ Standard tiles } \\
\hline RED BROWN & & 31.5 & 9.5 & 6.2 & 27.8 & 18.8 \\
\hline $10-\mathrm{S} 1$ & & 37.3 & 8.6 & 14.3 & 39.2 & 26.2 \\
\hline $10-\mathrm{S} 4$ & & 42.4 & 8.4 & 14.6 & 40.5 & 28.3 \\
\hline $17-B$ & & 50.7 & 4.4 & 8.6 & 38.6 & 29.7 \\
\hline $17-S 1$ & & 35.2 & 6.6 & 8.5 & 32.3 & 22.2 \\
\hline $17-S 3$ & & 44.1 & 6.1 & 15.7 & 37.0 & 26.5 \\
\hline \multicolumn{7}{|l|}{ Cool tiles } \\
\hline KB-E3 & & 31.7 & 5.6 & 5.1 & 40.0 & 25.9 \\
\hline KB-E4 & & 32.6 & 6.3 & 6.0 & 43.0 & 27.7 \\
\hline KB-E15 & & 34.8 & 7.8 & 8.3 & 45.6 & 29.5 \\
\hline KB-E16 & & 33.0 & 5.4 & 5.8 & 41.8 & 26.9 \\
\hline KB-E17 & & 35.9 & 8.2 & 9.1 & 48.0 & 31.5 \\
\hline KB-E30 & & 42.1 & 10.2 & 14.0 & 52.9 & 35.2 \\
\hline KB-E33 & & 34.5 & 7.3 & 7.5 & 44.8 & 28.9 \\
\hline KB-E34 & & 38.7 & 8.9 & 11.0 & 49.6 & 32.7 \\
\hline KB-E35 & & 37.6 & 9.1 & 11.0 & 48.2 & 31.5 \\
\hline
\end{tabular}

Cool tile prototypes exhibit a selective spectral behavior with high absorbance in the visible range (i.e. darkness in color) and improved reflectance in the NIR region (cooler surface). For instance, the two spectral reflectance curves of standard RED BROWN and cool KB-E16 shown in Fig. 4 perfectly match up to approximately $750 \mathrm{~nm}$ (maximum $\pm 2 \%$ of divergence) while the difference raises up to $35 \%$ in the NIR. From Table 3 it can be observed that in this case an improvement of solar reflectance of $+8.1 \%$ was achieved with the cool tile.

In general cool tile prototypes have demonstrated a significant solar reflectance improvement, between $7 \%$ and $10 \%$, depending on the tolerance for color or lightness variation. These results will be even more valuable considering that the standard ceramic tiles took as reference had already good reflecting properties ( $\mathrm{SR}=19-30 \%$, see Table 3 ) and the achieved solar reflectance values ( $\mathrm{SR}=26-35 \%$ ) can be compared with the best cool roof tiles today available (e.g. brown tiles from Cool Roof Rating Council database [13]), which definitely have not comparable aesthetic appearance. 


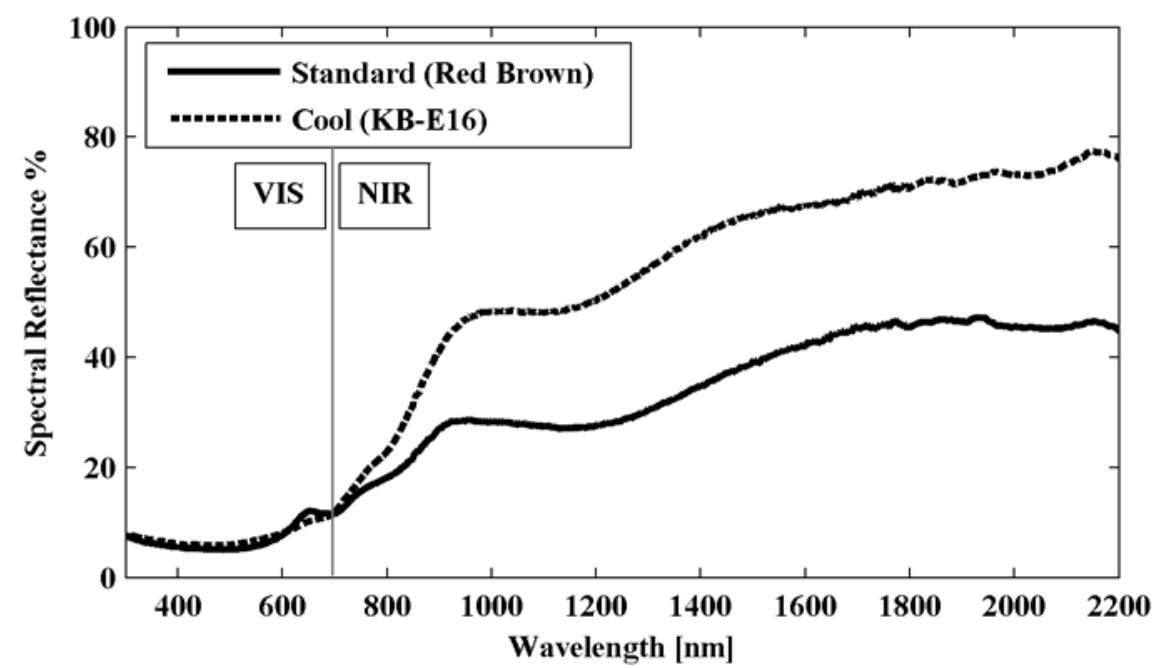

Fig. 4: Spectral reflectance curves for traditional (solid line) and cool tiles (dashed line).

\subsection{Cool Paints}

The aim of this work was to prepare water dispersions of nanoparticles that can be mixed with any commercial water-based acrylic paint, replacing the water required for thinning, in order to increase the NIR Reflectance of the commercial paint without affecting the commercial paint shade or other properties. Preliminary results will be discussed in order to better understand the effects of nanostructured oxides on NIR reflective properties and to identify the best oxides for the improvement of reflectivity without modifying color coordinates.

Four paint additive samples have been prepared, two with $\mathrm{TiO}_{2}$ and two with $\mathrm{Al}_{2} \mathrm{O}_{3}$, by dispersing the nanostructured oxide powders described in Table 1 in water. Samples Al_258_D11 (nanopowder A11) and Ti_259D11 (nanopowder Ti1) were prepared by forming a paste of the powder with water and a dispersive agent, and leaving it to wet for $6 \mathrm{~h}$ before adding the remaining water. Samples Al_591_G11 (nanopowder A12) and Ti_2604_H11 (nanopowder Ti3) were prepared by dispersing the powders in water using ultrasonication and a dispersive agent. Ultrasonication ensures the better dispersion of the powder in the water based additive. The nanopowder dispersions were mixed with a green commercial acrylic paint (RAL 6005, "Moss Green"), replacing the water needed for thinning, to a nanopowder concentration of $3.33 \% \mathrm{w} / \mathrm{v}$ in the final paint volume.

In Fig. 5 it can be observed that the use of selected nanostructured oxides as paint additives in water dispersions can improve the reflectance properties of original commercial paint. However a detailed analysis is required in order to determine a proper oxide composition, powder concentration, and particle size for the best trade-off between the two contrasting needs of keeping dark color and enhancing the reflectance at the same time. For instance, even if $\mathrm{TiO}_{2}$ can guarantee the maximum increment of NIR $(+8.7 \%)$ and solar reflectance $(+7.4 \%)$, the color change and the Lightness increase are still too high for a proper comparison with the original color (RAL 6005).

An optimal color matching and SR value have been achieved with the prototypes based on $\mathrm{Al}_{2} \mathrm{O}_{3}$ (samples Al_258_D11 and Al_591_G11) for which color differences inferior to 5 (respectively $\Delta \mathrm{E}=3 . \overline{3}$ and $\Delta \mathrm{E}=4.8$ ) with the reference RAL 6005 have been measured. 


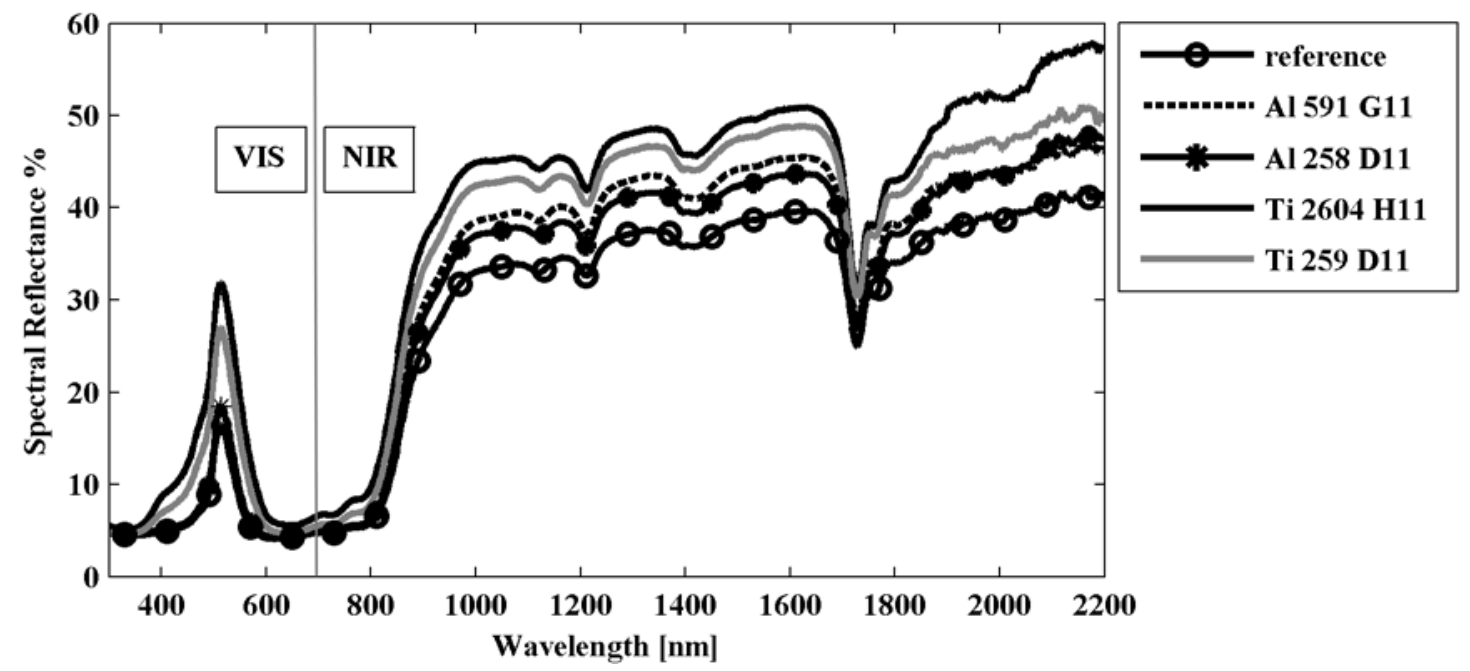

Fig. 5: Spectral reflectance of reference and cool paints with nanostructured oxide additives.

Table 4: Comparison between traditional and cool paints in terms of NIR/solar reflectance and CIELAB color coordinates.

\begin{tabular}{c|ccccccc}
\hline Sample & \multicolumn{1}{c}{ Appearance } & $\mathrm{L} *$ & $\mathrm{a}^{*}$ & $\mathrm{~b}^{*}$ & $\mathrm{R}_{\mathrm{NIR}} \%$ & $\mathrm{SR} \%$ & $\Delta \mathrm{E}$ \\
\hline reference & & 33.0 & -29.4 & 7.0 & 24.0 & 15.6 & - \\
Al_258_D11 & & 33.9 & -32.2 & 8.5 & 27.6 & 17.6 & 3.3 \\
Ti_259_D11 & & 41.5 & -38.5 & 6.9 & 30.6 & 20.8 & 12.5 \\
Al_591_G11 & & 34.1 & -33.9 & 8.4 & 26.7 & 17.2 & 4.8 \\
Ti_2604_H11 & & 46.7 & -45.3 & 7.3 & 32.7 & 23.0 & 21.0 \\
\hline
\end{tabular}

\section{Measurement of natural aging effects on conventional tiles and paints}

\subsection{Natural aging test procedure}

In parallel with the development of nanostructured cool materials, preliminary natural aging tests have been performed with the goal of identifying the main aging factors affecting reflective properties on traditional paints and tiles. This study will lay the bases for the development of dedicated accelerated procedures for the new materials.

18 glazed ceramic tiles ( 9 different colors and textures) and 14 concrete substrate tiles covered with acrylic paints ( 7 different colors) have been exposed for 4 months to outdoor

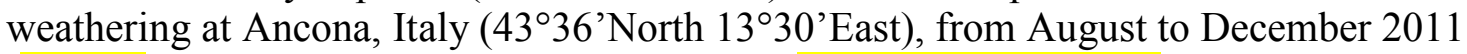
(Table 5). A low sloped ( $5^{\circ}$ from the horizontal, as suggested in [14], in order to avoid standing water), unbacked exposure configuration has been chosen. The nearly horizontal orientation has been chosen to simulate the end-use conditions which are, in our case, not only façades but also flat roofs and to maximize the effect of soiling in a short testing period even though the effect of solar radiation can be underestimated.

Weathering conditions have been continuously monitored by a weather station with a sampling time of 30 minutes (global values are reported in Table 6). Solar reflectance and color change have been assumed as main evaluation criteria for durability. The former represents the energy performance of materials while the latter is more linked to the aesthetic value. 
Soiling is expected to be one of the main factors responsible for the reflectance loss and its effect has to be distinguished from the contribution due to other weathering agents like solar radiation, temperature and relative humidity [15].

In order to split between the 2 different effects of weathering and soiling, samples have been separated in 2 groups: the first half was cleaned before the periodical evaluation and the second half was left soiled, paying attention during the handling and the shipping in order to avoid drop of dust from the surface. Following this approach it has been possible to quantify, for the considered set of samples:

- Natural aging due to atmospheric conditions (solar radiation, temperature and relative humidity) by comparing solar reflectance between initial and restored aged samples (in the latter case dust has been removed by rinsing specimens).

- Natural aging due to the combined actions of weathering and soiling (mainly dry and wet deposition of atmospheric aerosols and suspended particles) by monitoring reflectance loss on soiled samples.

Table 5: Ceramic tiles and painted concrete tiles exposed to outdoor weathering.

\begin{tabular}{|c|c|c|c|c|c|}
\hline \multicolumn{3}{|c|}{ Ceramic Tiles } & \multicolumn{3}{|c|}{ Concrete tiles with Acrylic Paints } \\
\hline Sample & Appearance & Initial SR\% & Sample & Appearance & Initial SR\% \\
\hline $\mathrm{t} 1$ & & 67.5 & p1 & & 82.9 \\
\hline $\mathrm{t} 2$ & & 47.1 & p2 & & 38.0 \\
\hline $\mathrm{t} 3$ & & 48.6 & p3 & & 48.8 \\
\hline t4 & & 35.3 & $\mathrm{p} 4$ & & 55.3 \\
\hline t5 & & 13.7 & p5 & . & 66.9 \\
\hline t6 & & 14.1 & p6 & & 71.2 \\
\hline $\mathrm{t} 7$ & & 36.9 & p7 & & 58.3 \\
\hline t8 & & 19.6 & & & \\
\hline t9 & & 57.2 & & & \\
\hline
\end{tabular}

Table 6: Climatic data measured during the outdoor exposure.

\begin{tabular}{lccc}
\hline & $\begin{array}{c}\text { Average } \mathbf{T}_{\text {amb }} \\
\left({ }^{\circ} \mathbf{C}\right)\end{array}$ & $\begin{array}{c}\text { Average RH } \\
(\mathbf{\%})\end{array}$ & $\begin{array}{c}\text { Daily average global } \\
\left.\text { solar radiation } \mathbf{( M J} / \mathbf{m}^{2}\right)\end{array}$ \\
\hline Month 1 (7/08-6/09) & 27.0 & 48.5 & 22.3 \\
Month 2 (7/09-6/10) & 23.3 & 61.9 & 16.8 \\
Month 3 (7/10-6/11) & 15.5 & 65.6 & 8.1 \\
Month 4 (7/11-6/12) & 11.5 & 73.9 & 5.4 \\
\hline
\end{tabular}

\section{2 - Weathering effect}

The effect of atmospheric agents (UV radiation, temperature and humidity) on material properties has been assessed by periodically measuring color and solar reflectance on rinsed samples. In fact, from a visual inspection it was seen that the soiling was mainly due to aerosol and suspended dust deposition and it has allowed to easily clean the surface and to compare initial and aged samples with restored properties.

Traditionally glazed tiles exhibit excellent durability and usually manage to preserve the original color for many years while the issue of color fading is well known in the paint 
industry. In both these cases the main purpose has been to quantify the color change and the loss of solar reflectance assessing at the same time the capability of paints and tiles in restoring initial reflectance values after cleaning.

From the histograms in Fig. 6 it can be observed that for ceramic tiles the restored solar reflectance has maintained at the initial value with a maximum variation inferior to $0.4 \%$ which is comparable to the accuracy interval of measurement, as shown in Par.2. Also the color has been preserved with an imperceptible maximum color change of $\Delta \mathrm{E}=0.4$ (sample t1).
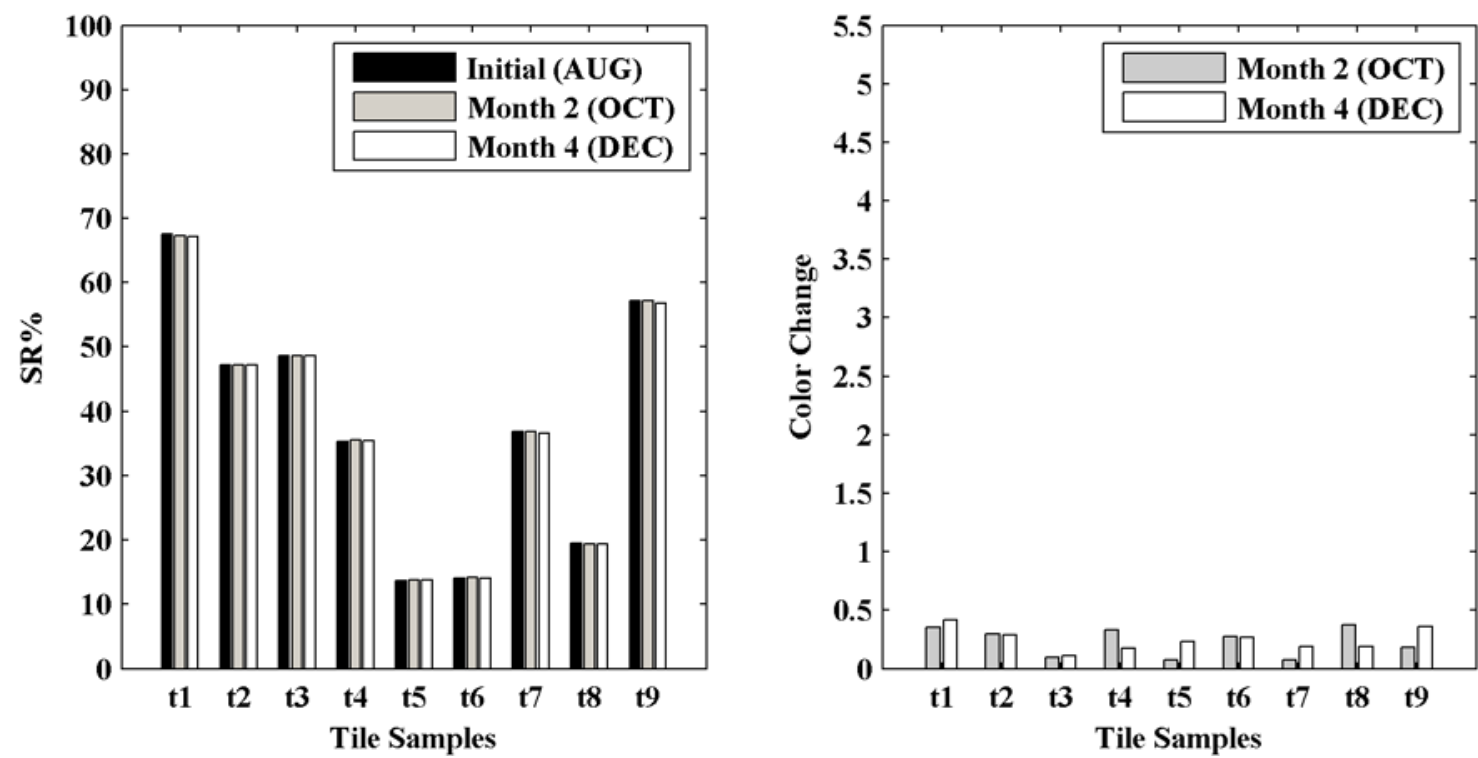

Fig. 6: Natural aging tests on glazed ceramic tile samples considering only atmospheric weathering: solar reflectance (left) and color change (right).

While glazed ceramic tiles have exhibited an optimal capability in retaining color and solar reflectance, painted samples undergo a significant loss of both these properties from the very beginning of the exposure period, as shown in Fig. 7. A relatively uniform trend was registered for the whole time of experiments, even in colder months, when the solar radiation is considerably reduced (Table 6). This behavior demonstrates that not only UV radiation, but also temperature, humidity and water condensation have a strong effect on reflectance reduction for acrylic paints. 

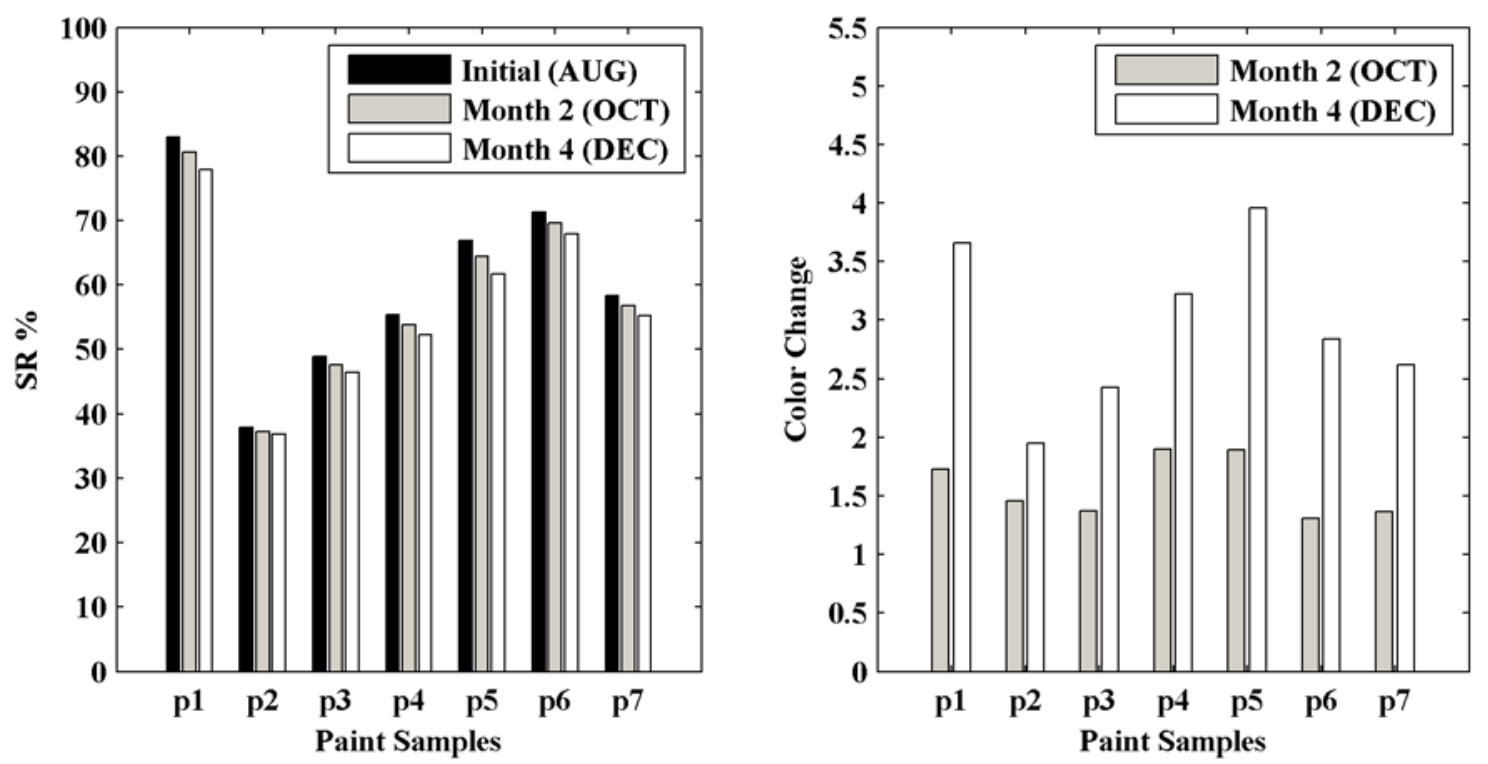

Fig. 7: Natural aging tests on acrylic paint samples considering only atmospheric weathering: solar reflectance (left) and color change (right).

After 4 months of outdoor exposure (from August to December 2011) the solar reflectance reduced from $-1 \%$ to $-5 \%$ (respectively for specimens $\mathrm{p} 2$ and $\mathrm{p} 1$ ) with a color change $(\Delta \mathrm{E})$ ranging from 2 to 4 , approaching the threshold of acceptability chosen for this study. As expected, both these properties have remarked a strong dependence on the initial properties: the higher is the initial solar reflectance, the higher is its drop due to weathering effects.

\section{3 -Combined weathering and soiling effects}

Beside weather conditions also soiling (dust and soot deposition, biological growth...) can have a huge effect on cool material performances. The combined actions of weathering and soiling on traditional tiles and paints have been therefore evaluated by measuring reflectance on analogous samples as those described in the previous section. The only difference is that in this case the specimens have not been cleaned allowing dust and soot to accumulate during the 4 months of exposure (particular attention has been paid during the sample shipping and handling).

While weathering had only effect on paints, from the analysis of Fig. 8 it comes out that soiling is an important issue also for ceramic tiles where a maximum decrease of $4 \%$ in solar reflectance (from 65 to $61 \%$ ) has been measured for the white sample (t1). However, even in this case, tiles still continue offering largely superior cooling performances compared to painted samples for which the loss of solar reflectance ranges from $-2.4 \%$ to $-9.8 \%$, corresponding respectively to samples $\mathrm{p} 2$ and $\mathrm{p} 1$. Considering that for the same samples the reduction due to the single weathering effect was respectively of $-1 \%$ and $-5 \%$ (Fig. 7 ) it appears that the contribution of weathering and soiling are of the same order of magnitude for paints (similar results have been found for all the samples under investigation). The necessity of taking into account for the combined effects of soiling and weathering, together with the long time required to perform a full natural test (3 years according to the Cool Roof Rating Council [13]) have raised in recent years the need of new international standards for accelerated aging procedure capable of reproducing the same effects in a shorter time. 



Fig. 8: Solar reflectance of aged samples considering the combined effect of soiling and weathering for glazed ceramic tiles (left) and acrylic paints (right).

\section{Conclusions}

The present study has shown first results obtained in the EU project COOL-Coverings aiming at improving the energy performances of traditional building envelope systems. Innovative colored cool tile and paint prototypes have been developed by integrating nanostructured metal oxides into traditional manufacturing processes. The main objective is to increase the reflectance properties of building envelope materials while keeping color freedom for architects and building constructors.

For brown glazed ceramic tiles it has been found that the combination of nanostructured metal oxides with other technological solutions has brought to a significant increase of NIR reflectance while keeping the color variation below the tolerant limit typical of tile manufacturing processes. A series of brown ceramic tiles with solar reflectance higher than $30 \%$ has been developed reaching (and in some cases exceeding) the performances of many cool materials with the same color currently available. Combining these improved reflective capabilities with excellent durability properties, the innovative cool ceramic tiles could represent an attractive alternative in the market of cool materials.

A similar approach has been adopted for green acrylic paints to be applied on different substrates. The dispersion of nanostructured $\mathrm{TiO}_{2}$ has provided the higher increase of solar reflectance $(+8.7 \%)$ while the use of $\mathrm{Al}_{2} \mathrm{O}_{3}$ as paint additive has guaranteed an optimal color matching.

Starting from these initial results, both for ceramic tiles and paints further improvements are expected in the following months by optimizing the nanostructured oxides selection, the particle size and reducing the quantity of contaminants.

In parallel with the development of new cool materials the effect of soiling and weathering on reflective properties during natural aging tests has been measured for traditional ceramic tiles and painted concrete tiles, aiming at laying the bases for dedicated accelerated procedures for 
new materials. As expected, it has been observed that ceramic tiles have optimal weathering resistance while samples with acrylic paints undergo a relevant degradation of reflective properties (both solar reflectance and color) from the very beginning of exposure period. This effect is increasing for highly reflecting paints and is caused by the combined actions of UV radiation, temperature and humidity. Soiling (in the present study mainly represented by dust deposition) has demonstrated to be another important aging factor influencing both paints and tiles. The soiling effect is mainly dependent on the initial solar reflectance value and for painted samples it has given an equal contribution to solar reflectance loss as weathering.

\section{Acknowledgments}

The COOL-Coverings project (www.coolcoverings.org) is partly funded by the EU Commission under the 7FP (EeB.NMP.2010-1, Grant Agreement 260132). The authors wish to thanks the functional centre of Civil Protection of Ancona for the collaboration.

\section{References}

1. Doulos L, Santamouris M, Livada I. Passive cooling of outdoor urban spaces. The role of materials. Solar Energy 2004; 77(2): 231-249.

2. Synnefa A, Santamouris M, Akbari H. Estimating the effect of using cool coatings on energy loads and thermal comfort in residential buildings in various climatic conditions. Energy and Buildings 2007; 39(11): 1167-1174.

3. Levinson R, Berdahl P, Akbari H, Miller W, Joedicke I, Reilly J, Suzuki J and Vondran M. Methods of creating solar-reflective nonwhite surfaces and their application to residential roofing materials. Solar Energy Materials \& Solar Cells 2007; 91(4): 304-314

4. Synnefa A, Santamouris M, Apostolakis K. On the development, optical properties and thermal performance of cool colored coatings for the urban environment. Solar Energy 2007, 81(4): 488-497.

5. Levinson R, Berdahl P, Akbari H. Solar spectral optical properties of pigments - PartII: survey of common colorants. Solar Energy Materials \& Solar Cells 2005; 89(4): 351389.

6. Levinson R, Akbari H, Berdahl P, Wood K, Skilton W, Petersheim J. A novel technique for the production of cool colored concrete tile and asphalt shingle roofing products. Solar Energy Materials \& Solar Cells 2010; 94(6): 946-954.

7. Jeevanandam P, Mulukutla R S, Phillips M, Chaudhuri S, Erickson L E, Klabunde K J. Near Infrared Reflectance Properties of Metal Oxide Nanoparticles. J Phys Chem C 2007; 111(5): 1912-1918.

8. Levinson R, Akbari H. Effects of composition and exposure on the solar reflectance of Portland cement concrete. Cement and Concrete Research 32(2002): 1679-1698.

9. Scarfato P, Di Maio L, Fariello M L, Russo P, Incarnato L. Preparation and evaluation of polymer/clay nanocomposite surface treatments for concrete durability enhancement. Cement and Concrete Composites; 2011.

10. Sleiman M, Destaillats H, Kirchstetter T, Gilbert H, Berdahl P, Akbari H, Marlot L, Quelen S, Preble C, Spears M, Ban-Weiss G, Levinson R. LBNL accelerated aging protocols, International Workshop on Advances in Cool Roof Research. Berkeley, CA, July 28 \& 29, 2011; http://coolroofs2011.lbl.gov/.

11. ASTM Standard E903-96 Standard test method for solar absorptance, reflectance and transmittance of materials using integrating sphere.

12. ASTM Standard G173-03 (2008) Standard tables for reference solar spectral irradiances: direct normal and hemispherical on $37^{\circ}$ tilted surface.

13. Cool Roof Rating Council (CRRC), http://www.coolroofs.org/. 
14. ASTM Standard G7 (2011) Standard practice for atmospheric environmental exposure testing of nonmetallic materials

15. Sleiman M, Ban-Weiss G, Gilbert H E, François D, Berdahl P, Kirchstetter T, Destaillats $\mathrm{H}$, Levinson R. Soiling of building envelope surfaces and its effect on solar reflectance Part I: Analysis of roofing product databases. Solar Energy Materials \& Solar Cells 2011; 95(12): 3385-3399. 